\title{
Gender differences in knowledge, attitudes and preparedness to respond to COVID-19 among adults in Bangladesh: A cross-sectional study
}

\author{
Mst. Sadia Sultana ${ }^{1}$, Abid Hasan Khan ${ }^{1}$, Md. Raisul Islam ${ }^{1}$, Sahadat Hossain ${ }^{1}$, M. Tasdik Hasan ${ }^{2,3,4}$, Md. Tajuddin Sikder $^{1}$
}

\author{
AFFILIATION \\ 1 Department of Public Health and Informatics, Jahangirnagar University, \\ Dhaka, Bangladesh \\ 2 Department of Public Health, State University of Bangladesh, Dhaka, \\ Bangladesh \\ 3 Jeeon Bangladesh Ltd., Dhaka, Bangladesh \\ 4. Department of Primary Care and Mental Health, University of Liverpool, \\ Liverpool, United Kingdom
}

CORRESPONDENCE TO

Mst. Sadia Sultana. Department of Public Health and Informatics,

Popul. Med. 2022;4(January):5
Jahangirnagar University, Dhaka, 1342, Bangladesh.

E-mail: sadiasuhi.ju@gmail.com

ORCID ID: https://orcid.org/0000-0002-3991-4198

KEYWORDS

knowledge, attitudes, preparedness, COVID-19, gender, Bangladesh

Received: 31 March 2021, Revised: 23 July 2021,

Accepted: 12 January 2022

https://doi.org/10.18332/popmed/145763

\begin{abstract}
INTRODUCTION Effective pandemic management requires understanding the level of community knowledge, attitudes of people, and preparedness towards COVID-19. This study aimed to assess gender differences regarding knowledge, attitudes and preparedness toward the COVID-19, among Bangladeshi adults.

METHODS A cross-sectional survey was conducted MarchApril 2020 among 1050 Bangladeshi adults. A convenience sampling strategy was utilized, and the data were collected online through a self-administered questionnaire. Chisquared tests were used to identify the gender differences regarding knowledge, attitudes and preparedness towards COVID-19.

RESULTS Respondents predominately used social media to inform themselves about COVID-19 (68.1\%), and females used social media more than males $(p<0.001)$. Females
\end{abstract}

had higher levels of correct knowledge about staying home with sickness and symptoms to prevent the COVID-19 transmission $(\mathrm{p}=0.02)$. Males had a more negative attitude about staying out during the pandemic than females $(p<0.001)$; men were less likely to take preventative measures than their female counterparts. Some people believed in misinformation like 'COVID-19 can transmit via mosquitos' (9.1\%), and males had more incorrect knowledge regarding this $(\mathrm{p}<0.001)$. Moreover, $17.8 \%$ of the respondents thought that COVID-19 could spread in warm weather.

CONCLUSIONS Males showed a higher tendency to believe the myths about COVID-19 than their female counterparts, which is alarming. Awareness programs should be emphasized, focusing on gender-specific pertinent information to ensure effective preventative measures.

\section{INTRODUCTION}

The unprecedented global health crisis due to the COVID-19 pandemic has brought critical challenges to public health with over 364 million cases and 5.6 million deaths worldwide as of 28 January $2022^{1}$. The first case of COVID-19 in Bangladesh was declared on 8 March 2020 by the Institution of Epidemiology, Disease Control and Research (IEDCR) ${ }^{2}$. Since then, the situation has been deteriorating. Bangladesh faces a critical problem with 1.7 million confirmed cases and 28288 deaths as of 28 January $2022^{1}$. This relatively higher mortality has led the global scientific community to focus on research for the development of treatments, vaccines and preventive strategies ${ }^{3}$. But the efficient handling of the pandemic calls for help from the vulnerable population for efforts to alleviate the transmission of the pandemic ${ }^{4}$. Knowledge about COVID-19 symptoms, transmission and prevention is crucial because better knowledge equates with stronger precautionary practices ${ }^{5}$. Insufficient information and wrong attitudes contribute to delayed diagnoses, ineffective infection management and lack of personal hygiene $^{6}$. Testing, tracing, and masks can all be effective methods of limiting transmission of the COVID-19 in dynamic community settings, and better compliance with one can compensate for weaker compliance with the other, to some 
extent ${ }^{7}$. When a population has correct knowledge, positive attitudes and better preparedness towards COVID-19, it is able to better impede COVID-19 transmission. Various studies have reported that assessing expertise and awareness regarding the disease is important to combat any infectious disease $^{8,9}$. Poor knowledge about transmission affects the control measures, as the spread rate of infectious disease has been found higher among populations with poor knowledge about the disease ${ }^{10}$. A study conducted among healthcare workers in China showed that attitudes and practices about COVID-19 were impacted by several risk factors, including work experience and job category ${ }^{11}$.

To date, male vulnerability has been observed with 54$73 \%$ of all COVID-19 infections in men ${ }^{12}$. Low knowledge about COVID-19 transmission and prevention may attribute this high infection rate in men, which requires research exploration. Furthermore, the crucial understanding of the epidemiological pattern of this epidemic and the efficacy and effectiveness of public health interventions depend on the awareness, behavior and behaviors of the general population towards COVID-19 ${ }^{13}$. Though COVID-19 affected both genders, males and females have different preventive behaviors and perceptions towards this pandemic ${ }^{14}$. Females were well informed and had a better attitude to the prevention measures of the disease ${ }^{15}$. A study in the United States showed that a higher percentage of females were practicing preventive behaviors during this recent outbreak ${ }^{14}$. A survey conducted among Bangladeshi youth found that only 51.6\% had good practices, whereas $61.2 \%$ had adequate knowledge and $78.9 \%$ had positive attitudes regarding COVID-19 ${ }^{16}$. Moreover, another study from Bangladesh demonstrated that female sex, older age, higher education level, family income $>30000$ BDT (1000 Bangladeshi Takas about US $\$ 12$ ), urban area location, and more positive attitudes were linked with more frequent preventive practices ${ }^{17}$. But there are no studies assessing the gender differences regarding knowledge, attitudes and preparedness toward the COVID-19 among Bangladeshi adults, which implies a knowledge gap.

Considering the importance of investigating the community's knowledge, attitude and preparedness, this study aimed to address that knowledge gap by assessing gender differences toward the COVID-19 among Bangladeshi adults, which will help to initiate suitable health education programs for the community. We hypothesize that females would have more appropriate knowledge, better attitude and preparedness towards the COVID-19 than their male counterparts.

\section{METHODS}

\section{Study design and participants}

A cross-sectional study was conducted through an online survey among the general population of Bangladesh. The study was conducted following the Checklist for Reporting Results of Internet ESurveys (CHERRIES) guidelines ${ }^{18}$. Inclusion criteria were: being Bangladeshi, willing to participate, age $\geq 18$ years, able to understand Bangla language, and residing in Bangladesh during the survey. Respondents who were unwilling to provide electronically informed consent were excluded from the study. A convenience sampling technique and online data collection method were chosen to meet the study aims, as face-to-face interviewing was risky.

\section{Data collection}

Data collection took place March-April 2020. Responses came from 1050 participants (aged 18-68 years). An online structured questionnaire was developed using Google Forms as the data collection tool. The questionnaire was pre-tested with a small group (30 participants) to ensure its transparency and to avoid any inconsistencies in the questionnaire. The questionnaire link was disseminated online on different social media (i.e. Facebook, What's App, Instagram, Telegram, Viber). For ensuring the quality of data, rapid checking of data was done every day. An information sheet describing the aim and process, right to refuse participation in the study was presented on the first page of the survey, attaching an electronic consent form. Participants were informed that their information would only be used for the research. The respondents voluntarily participated in the study, and no financial incentive was provided to them. Anonymity and confidentially were ensured. All the procedures of this study complied with the Code of Ethics of the World Medical Association (Declaration of Helsinki) for any experiments involving humans and Ethical clearance certificate for this study was obtained from the Institutional Review Board ${ }^{19}$, 'Biosafety, Biosecurity \& Ethical Committee' of the Jahangirnagar University. After giving informed consent, participants voluntarily proceeded with the survey. It took participants about 10-15 minutes to complete the survey.

\section{Measures}

The questionnaire of this study was developed by gathering information from the literature ${ }^{20,21}$. When the questionnaire draft was created, it was reviewed and revised several times to fully align with the study's objectives. A questionnaire review panel of three experts, in global mental health research, public health, and public health research, evaluated and revised the questionnaire to cover the study's objectives. The questionnaire was updated and resent to the review panel based on their comments and suggestions for approval to begin pre-testing.

\section{Sociodemographic characteristics}

Demographic variables included age, gender, number of family members, name of the residing district, educational level, and occupation. Educational level had three subcategories:1) higher secondary; 2) honors or above; and 3) up to secondary.

\section{Knowledge, attitude and preparedness information}

The questionnaire included 29 questions about COVID-19 knowledge, 5 questions about attitudes and 9 questions 
about preparedness towards the COVID-19. Questions about the source of knowledge on COVID-19 symptoms (most common symptoms), transmission and prevention were administered by collecting information from the existing literature. Close-ended questions ascertained attitudes towards COVID-19. Preparedness towards COVID-19 was also assessed. The questions had two response options, either 'yes' or 'no'.

\section{Statistical analysis}

Data were analyzed with STATA version 14.1 (StataCorpLP, College Station, TX, USA). Microsoft Excel was used for editing, sorting and coding of data. Descriptive statistics such as frequency and percentage were obtained to understand participants' characteristics. Chi-squared tests were performed to identify the gender differences regarding knowledge, attitude and preparedness towards COVID-19. A $\mathrm{p} \leq 0.05$ was considered statistically significant for all analyses.

\section{RESULTS}

\section{Sociodemographic characteristics}

Respondents' sociodemographic characteristics are given in Table 1. In all, $65.9 \%$ of respondents were aged $<25$ years; the majority were male (63.4\%);most respondents had an educational level equivalent to honors or above (83.5\%); and respondents were primarily students (76.2\%), but there were also government or private service holders (14.38\%) and others such as housewives and freelancers (9.4\%).

\section{Knowledge of COVID-19}

Almost all the respondents knew about the virus (98.5\%), and the majority acknowledged the virus to be extremely dangerous (86.3\%). Most respondents came to know about the virus via social media (68.1\%). Respondents' response to 'How did you first come to know about the virus?' differed by gender $(\mathrm{p}<0.001)$.

Knowledge of COVID-19 symptoms, transmission, and prevention

With regard to symptoms for COVID-19, male respondents did not know that diarrhea (59.85\%), muscle pain (58.1\%), fatigue $(55.3 \%)$, and vomiting $(69.7 \%)$ were symptoms of COVID-19, while the corresponding proportions for females were $44.5 \%, 61.2 \%, 57.7 \%$ and $67.7 \%$. These responses had no significant association with the gender of the respondents (Table 2).

With regard to the transmission of COVID-19, male respondents had incorrect knowledge of COVID-19 transmission as they did not know that eating with unclean/ unwashed hands $(28.8 \%)$, touching face with unclean hands $(14.6 \%)$ and public transport (30.3\%) can facilitate transmission of the infection. These responses did not differ by gender of the respondents (Table 2). However, the answers to 'Do you think COVID-19 can spread via mosquitos?' differed by gender $(\mathrm{p}<0.001)$.
Using a tissue while coughing or sneezing was the most reported prevention method for COVID-19 (98.57\%). Most respondents thought that COVID-19 could not spread in warm weather $(82.2 \%)$. On the other hand, most respondents knew that only a mask is insufficient to prevent the virus transmission (98\%), and $89.6 \%$ correctly reported that antibiotics cannot cure COVID-19. Only $6.5 \%$ of males and $3.1 \%$ of females did not know that staying home could be a way to prevent COVID-19. The response to 'Staying home if sick can prevent COVID-19' also differed by gender $(\mathrm{p}=0.02)$.

\section{Attitude towards COVID-19}

More than half of the respondents were apprehensive about COVID-19 (51.9\%). More than half of the respondents are still going out, and they reported the duration of staying out as less than half an hour (41.8\%), half an hour to 2 hours (9.1\%), 2 to 4 hours (1.3\%) and more than 4 hours (3.0\%). The responses for 'Are you worried about COVID-19' differed by gender $(\mathrm{p}=0.02)$. Again, the answers for 'How long do you stay out lately' differed by gender $\left[\chi^{2}(4, N=1050)=67.78\right.$, $\mathrm{p}<0.001$ ] (Table 3).

\section{Preparedness for COVID-19}

Most respondents reported consulting a doctor if they have COVID-19 like symptoms (85.5\%). The responses for 'Do you wash your hands with just water?' differed by gender $\left[\chi^{2}(1, N=1050)=7.41, p=0.01\right]$. Similarly, the

Table 1. Sociodemographics of the study participants, Bangladesh March-April 2020 ( $N=1050)$

\begin{tabular}{lc}
\hline Variables & $\mathbf{n}(\%)$ \\
\hline Age $($ years $)$ & \\
\hline$<25$ & $692(65.90)$ \\
$25-35$ & $320(30.48)$ \\
$>35$ & $38(3.62)$ \\
Gender & \\
\hline Male & $666(63.43)$ \\
Female & $384(36.57)$ \\
\hline Family members & \\
$<5$ & $524(49.90)$ \\
\hline $5-6$ & $398(37.90)$ \\
$>6$ & $128(12.19)$ \\
\hline Education level & \\
Up to secondary & $37(3.52)$ \\
Higher secondary & $136(12.95)$ \\
Honors or above & $877(83.52)$ \\
\hline Occupation & \\
\hline Student & $800(76.19)$ \\
Government/private services & $151(14.38)$ \\
Other & $99(9.43)$
\end{tabular}


Table 2. Knowledge of COVID-19 by gender, Bangladesh March-April 2020 (N=1050)

\begin{tabular}{|c|c|c|c|c|c|}
\hline Variables & $\begin{array}{l}\text { Total } \\
\text { n (\%) }\end{array}$ & $\begin{array}{c}\text { Male } \\
(n=666) \\
n(\%)\end{array}$ & $\begin{array}{c}\text { Female } \\
(n=384) \\
n(\%)\end{array}$ & $X^{2}[\mathbf{d f}]$ & $\mathbf{p}$ \\
\hline \multicolumn{6}{|c|}{ Do you know about COVID-19? } \\
\hline Yes & $1034(98.48)$ & $657(98.65)$ & 377 (98.18) & $0.36[1]$ & 0.55 \\
\hline No & $16(1.52)$ & $9(1.35)$ & $7(1.82)$ & & \\
\hline \multicolumn{6}{|c|}{$\begin{array}{l}\text { How did you first come to know about the } \\
\text { virus? }\end{array}$} \\
\hline Newspaper & $73(6.95)$ & $61(9.16)$ & $12(3.13)$ & $19.10[3]$ & $<0.001^{* *}$ \\
\hline Mass media (e.g. TV) & $218(20.76)$ & 137 (20.57) & $81(21.09)$ & & \\
\hline Social media & $715(68.10)$ & 448 (67.27) & $267(69.53)$ & & \\
\hline Doctor or family & $44(4.19)$ & $20(3.00)$ & $24(6.25)$ & & \\
\hline \multicolumn{6}{|c|}{ How dangerous is the virus? } \\
\hline Slightly & $144(13.71)$ & $92(13.81)$ & $52(13.54)$ & $0.02[1]$ & 0.90 \\
\hline Extremely & $906(86.29)$ & $574(86.19)$ & $332(86.46)$ & & \\
\hline \multicolumn{6}{|c|}{ Knowledge of COVID-19 symptoms } \\
\hline \multicolumn{6}{|c|}{ Is fever a symptom of COVID-19? } \\
\hline Yes & $1035(98.57)$ & $655(98.35)$ & $380(98.96)$ & $0.64[1]$ & 0.42 \\
\hline No & $15(1.43)$ & $11(1.65)$ & $4(1.04)$ & & \\
\hline \multicolumn{6}{|c|}{ Is a dry cough a symptom of COVID-19? } \\
\hline Yes & 1010 (96.19) & $644(96.70)$ & $366(95.31)$ & $1.27[1]$ & 0.26 \\
\hline No & $40(3.81)$ & $22(3.30)$ & $18(4.69)$ & & \\
\hline \multicolumn{6}{|c|}{$\begin{array}{l}\text { Is difficulty breathing a symptom of } \\
\text { COVID-19? }\end{array}$} \\
\hline Yes & $1011(96.29)$ & $642(96.40)$ & 369 (96.09) & $0.06[1]$ & 0.80 \\
\hline No & $39(3.71)$ & $24(3.60)$ & $15(3.91)$ & & \\
\hline \multicolumn{6}{|c|}{ Is a sore throat a symptom of COVID-19? } \\
\hline Yes & $891(84.86)$ & $571(85.74)$ & $320(83.33)$ & $1.09[1]$ & 0.30 \\
\hline No & $159(15.14)$ & $95(14.26)$ & $64(16.67)$ & & \\
\hline \multicolumn{6}{|c|}{ Is diarrhea a symptom of COVID-19? } \\
\hline Yes & $547(52.10)$ & $334(50.15)$ & $213(55.47)$ & $2.76[1]$ & 0.10 \\
\hline No & $503(47.90)$ & $332(49.85)$ & $171(44.53)$ & & \\
\hline \multicolumn{6}{|c|}{ Is fatigue a symptom of COVID-19? } \\
\hline Yes & $460(43.85)$ & $298(44.74)$ & $162(42.30)$ & $0.59[1]$ & 0.44 \\
\hline No & $589(56.15)$ & $368(55.26)$ & $221(57.70)$ & & \\
\hline \multicolumn{6}{|c|}{ Is muscle pain a symptom of COVID-19? } \\
\hline Yes & $428(40.76)$ & 279 (41.89) & $149(38.80)$ & $0.96[1]$ & 0.33 \\
\hline No & $622(59.24)$ & $387(58.11)$ & $235(61.20)$ & & \\
\hline \multicolumn{6}{|c|}{ Is vomiting a symptom of COVID-19? } \\
\hline Yes & $326(31.05)$ & $202(30.33)$ & $124(32.29)$ & $0.44[1]$ & 0.51 \\
\hline No & $724(68.95)$ & $464(69.67)$ & $260(67.71)$ & & \\
\hline \multicolumn{6}{|c|}{ Knowledge of COVID-19 transmission } \\
\hline \multicolumn{6}{|c|}{$\begin{array}{l}\text { COVID-19 spreads through coughing or } \\
\text { sneezing }\end{array}$} \\
\hline Yes & $1032(98.29)$ & $656(98.50)$ & $376(97.92)$ & $0.49[1]$ & 0.48 \\
\hline No & $18(1.71)$ & $10(1.50)$ & $8(2.08)$ & & \\
\hline
\end{tabular}


Table 2. Continued

\begin{tabular}{|c|c|c|c|c|c|}
\hline Variables & $\begin{array}{l}\text { Total } \\
\text { n (\%) }\end{array}$ & $\begin{array}{c}\text { Male } \\
(n=666) \\
n(\%)\end{array}$ & $\begin{array}{c}\text { Female } \\
(n=384) \\
n(\%)\end{array}$ & $\chi^{2}[\mathbf{d f}]$ & $\mathbf{p}$ \\
\hline \multicolumn{6}{|c|}{$\begin{array}{l}\text { COVID-19 spreads through close contact } \\
\text { with infected person }\end{array}$} \\
\hline Yes & $1036(98.67)$ & $654(98.20)$ & $382(99.48)$ & $3.04[1]$ & 0.08 \\
\hline No & $14(1.33)$ & $12(1.80)$ & $2(0.52)$ & & \\
\hline \multicolumn{6}{|c|}{$\begin{array}{l}\text { COVID-19 spreads through contaminated } \\
\text { surface }\end{array}$} \\
\hline Yes & $979(93.24)$ & $621(93.24)$ & $45(6.76)$ & $<0.001[1]$ & 0.99 \\
\hline No & $71(6.76)$ & $358(93.23)$ & $26(6.77)$ & & \\
\hline \multicolumn{6}{|c|}{$\begin{array}{l}\text { COVID-19 spreads through eating with } \\
\text { unclean hands }\end{array}$} \\
\hline Yes & $753(71.71)$ & 474 (71.17) & $279(72.66)$ & $0.26[1]$ & 0.61 \\
\hline No & 297 (28.29) & $192(28.83)$ & $102(27.34)$ & & \\
\hline \multicolumn{6}{|c|}{$\begin{array}{l}\text { COVID-19 spreads through touching face } \\
\text { with unclean hands }\end{array}$} \\
\hline Yes & $906(86.29)$ & $569(85.44)$ & $337(87.76)$ & $1.11[1]$ & 0.29 \\
\hline No & $144(13.71)$ & $97(14.56)$ & $47(12.24)$ & & \\
\hline \multicolumn{6}{|c|}{$\begin{array}{l}\text { COVID-19 can spread via use of public } \\
\text { transport }\end{array}$} \\
\hline Yes & $713(67.90)$ & $464(69.67)$ & $249(64.84)$ & $2.60[1]$ & 0.11 \\
\hline No & $337(32.10)$ & $202(30.33)$ & $135(35.16)$ & & \\
\hline \multicolumn{6}{|c|}{$\begin{array}{l}\text { Do you think COVID-19 can spread via } \\
\text { mosquitos? }\end{array}$} \\
\hline Yes & $96(9.14)$ & $78(11.71)$ & $18(4.69)$ & $14.47[1]$ & $<0.001^{* *}$ \\
\hline No & $954(90.86)$ & 588 (88.29) & $366(95.31)$ & & \\
\hline \multicolumn{6}{|c|}{$\begin{array}{l}\text { Do you think COVID-19 can't spread in } \\
\text { warm weather? }\end{array}$} \\
\hline Yes & 863 (82.19) & $555(83.33)$ & $308(80.21)$ & $1.63[1]$ & 0.20 \\
\hline No & $187(17.81)$ & $111(16.67)$ & $76(19.79)$ & & \\
\hline \multicolumn{6}{|c|}{ Knowledge of COVID-19 prevention } \\
\hline \multicolumn{6}{|c|}{ Use tissue while coughing or sneezing } \\
\hline Yes & $1035(98.57)$ & $653(98.05)$ & $382(99.48)$ & $3.54[1]$ & 0.06 \\
\hline No & $15(1.43)$ & $13(1.95)$ & $2(0.52)$ & & \\
\hline \multicolumn{6}{|c|}{$\begin{array}{l}\text { Wash hands with soap or using hand- } \\
\text { sanitizers }\end{array}$} \\
\hline Yes & $1034(98.48)$ & $653(98.05)$ & $381(99.22)$ & $2.22[1]$ & 0.14 \\
\hline No & $16(1.52)$ & 13 (1.95) & $3(0.78)$ & & \\
\hline \multicolumn{6}{|c|}{ Avoid crowds } \\
\hline Yes & $1023(97.43)$ & $648(97.30)$ & $375(97.66)$ & $0.13[1]$ & 0.72 \\
\hline No & $27(2.57)$ & $18(2.70)$ & $9(2.34)$ & & \\
\hline \multicolumn{6}{|c|}{ Stay home if sick } \\
\hline Yes & $995(94.76)$ & $623(93.54)$ & $372(96.88)$ & $5.45[1]$ & $0.02 *$ \\
\hline No & $55(5.24)$ & $43(6.46)$ & $12(3.13)$ & & \\
\hline \multicolumn{6}{|c|}{ Is a mask enough to prevent the virus? } \\
\hline Yes & $21(2.00)$ & $14(2.10)$ & 7 (1.82) & 0.10 [1] & 0.76 \\
\hline No & $1029(98.00)$ & $652(97.90)$ & 377 (98.18) & & \\
\hline
\end{tabular}


Table 2. Continued

\begin{tabular}{|c|c|c|c|c|c|}
\hline Variables & $\begin{array}{l}\text { Total } \\
\text { n (\%) }\end{array}$ & $\begin{array}{c}\text { Male } \\
(n=666) \\
n(\%)\end{array}$ & $\begin{array}{c}\text { Female } \\
(n=384) \\
n(\%)\end{array}$ & $\chi^{2}[\mathbf{d f}]$ & $\mathbf{p}$ \\
\hline \multicolumn{6}{|c|}{ Can antibiotics cure from COVID-19? } \\
\hline Yes & $109(10.38)$ & $60(9.01)$ & 49 (12.79) & $3.68[1]$ & 0.06 \\
\hline No & 941 (89.62) & 606 (90.99) & 335 (87.24) & & \\
\hline \multicolumn{6}{|c|}{ Boiling food properly } \\
\hline Yes & $810(77.14)$ & $502(75.38)$ & $308(80.21)$ & $3.23[1]$ & 0.07 \\
\hline No & $240(22.86)$ & $164(24.62)$ & 76 (19.79) & & \\
\hline \multicolumn{6}{|c|}{ Isolating infected person } \\
\hline Yes & $1002(95.43)$ & $631(94.74)$ & $371(96.61)$ & $1.95[1]$ & 0.16 \\
\hline No & $48(4.57)$ & $35(5.26)$ & 13 (3.39) & & \\
\hline \multicolumn{6}{|c|}{ Avoid touching face with unclean hands } \\
\hline Yes & $989(94.19)$ & $625(93.84)$ & $364(94.79)$ & $0.40[1]$ & 0.53 \\
\hline No & $61(5.81)$ & $41(6.16)$ & $20(5.21)$ & & \\
\hline \multicolumn{6}{|c|}{ Safe disposal of used tissues } \\
\hline Yes & $951(90.57)$ & $602(90.39)$ & 349 (90.89) & $0.07[1]$ & 0.79 \\
\hline No & $99(9.43)$ & $64(9.61)$ & $35(9.11)$ & & \\
\hline
\end{tabular}

${ }^{*} \mathrm{p}<0.05 ;{ }^{*} \mathrm{p}<0.01 . \mathrm{df}=$ degrees of freedom.

Table 3. Attitude towards COVID-19 by gender, Bangladesh March-April 2020 (N=1050)

\begin{tabular}{|c|c|c|c|c|c|}
\hline Variables & $\begin{array}{l}\text { Total } \\
\text { n (\%) }\end{array}$ & $\begin{array}{c}\text { Male } \\
(n=666) \\
n(\%)\end{array}$ & $\begin{array}{c}\text { Female } \\
(n=384) \\
n(\%)\end{array}$ & $\chi^{2}[\mathrm{df}]$ & $\mathbf{p}$ \\
\hline \multicolumn{6}{|c|}{ Are you worried about COVID-19? } \\
\hline Worried & $477(45.33)$ & $290(43.54)$ & $187(48.70)$ & $7.73[2]$ & $0.02 *$ \\
\hline Very worried & $545(51.90)$ & $352(52.85)$ & $193(50.26)$ & & \\
\hline Not worried & $28(2.67)$ & $24(3.60)$ & $4(1.04)$ & & \\
\hline \multicolumn{6}{|c|}{$\begin{array}{l}\text { Would you be in quarantine if you have } \\
\text { COVID-19 like symptoms? }\end{array}$} \\
\hline Yes & $1031(98.19)$ & $654(98.20)$ & $377(98.18)$ & $<0.001[1]$ & 0.98 \\
\hline No & $19(1.81)$ & $12(1.80)$ & $7(1.82)$ & & \\
\hline \multicolumn{6}{|c|}{ How long do you stay out lately? } \\
\hline I don't go out & $471(44.86)$ & $236(35.44)$ & $235(61.20)$ & $67.78[4]$ & $<0.001^{* *}$ \\
\hline$<30 \mathrm{~min}$ & $439(41.81)$ & $319(47.90)$ & $120(31.25)$ & & \\
\hline $30 \mathrm{~min}$ to $2 \mathrm{~h}$ & $95(9.05)$ & $76(11.41)$ & $19(4.95)$ & & \\
\hline $2-4 \mathrm{~h}$ & $14(1.33)$ & $10(1.50)$ & $4(1.04)$ & & \\
\hline$>4 \mathrm{~h}$ & $31(2.95)$ & $25(3.75)$ & $6(1.56)$ & & \\
\hline \multicolumn{6}{|c|}{$\begin{array}{l}\text { Would you make aware your relatives } \\
\text { about the virus? }\end{array}$} \\
\hline Yes & $994(94.67)$ & $626(93.99)$ & $368(95.83)$ & $1.63[1]$ & 0.20 \\
\hline No & $56(5.33)$ & $40(6.01)$ & $16(4.17)$ & & \\
\hline \multicolumn{6}{|c|}{$\begin{array}{l}\text { Would you move as before if you have } \\
\text { COVID-19 like symptoms? }\end{array}$} \\
\hline Yes & $25(2.38)$ & $16(2.40)$ & $9(2.34)$ & $0.004[1]$ & 0.95 \\
\hline No & $1025(97.62)$ & $650(97.60)$ & $375(97.66)$ & & \\
\hline
\end{tabular}

${ }^{*} \mathrm{p}<0.05 ;{ }^{* *} \mathrm{p}<0.01 . \mathrm{df}=$ degrees of freedom. 
Table 4. Preparedness for COVID-19 by gender, Bangladesh March-April 2020 ( $\mathrm{N}=1050)$

\begin{tabular}{|c|c|c|c|c|c|}
\hline Variables & $\begin{array}{l}\text { Total } \\
\text { n (\%) }\end{array}$ & $\begin{array}{c}\text { Male } \\
(n=666) \\
n(\%)\end{array}$ & $\begin{array}{c}\text { Female } \\
(n=384) \\
n(\%)\end{array}$ & $\chi^{2}[\mathbf{d f}]$ & $\mathbf{p}$ \\
\hline \multicolumn{6}{|c|}{ How frequently do you use a mask? } \\
\hline Never & $50(4.76)$ & $29(4.35)$ & $21(5.47)$ & $0.67[2]$ & 0.72 \\
\hline Sometimes & $513(48.86)$ & $327(49.10)$ & $186(48.44)$ & & \\
\hline Always & $487(46.38)$ & $310(46.38)$ & $177(46.09)$ & & \\
\hline \multicolumn{6}{|c|}{$\begin{array}{l}\text { How frequently do you wash your hands } \\
\text { in a day(times)? }\end{array}$} \\
\hline 0 & $1(0.10)$ & $1(0.15)$ & $0(0)$ & $1.23[2]$ & 0.54 \\
\hline $1-3$ & $94(8.95)$ & $56(8.41)$ & $38(9.90)$ & & \\
\hline$>4$ & $955(90.95)$ & $609(91.44)$ & $346(90.10)$ & & \\
\hline \multicolumn{6}{|c|}{ Do you wash your hands with just water? } \\
\hline Yes & $70(6.67)$ & $55(8.26)$ & $15(3.91)$ & $7.41[1]$ & $0.01^{* *}$ \\
\hline No & $980(93.33)$ & $611(91.74)$ & $369(96.09)$ & & \\
\hline \multicolumn{6}{|c|}{ Do you wash your hands with handwash? } \\
\hline Yes & $795(75.71)$ & $473(71.02)$ & $322(83.85)$ & $21.81[1]$ & $<0.001^{* *}$ \\
\hline No & $255(24.29)$ & $193(28.98)$ & $62(16.15)$ & & \\
\hline \multicolumn{6}{|c|}{ Do you wash your hands with soap? } \\
\hline Yes & $659(62.76)$ & $444(66.67)$ & 215 (55.99) & $11.88[1]$ & $<0.001^{* *}$ \\
\hline No & $391(37.24)$ & $222(33.33)$ & $169(44.01)$ & & \\
\hline \multicolumn{6}{|c|}{$\begin{array}{l}\text { Would you consult a doctor if you have } \\
\text { COVID-19 like symptoms? }\end{array}$} \\
\hline Yes & $897(85.51)$ & $569(85.44)$ & $328(85.64)$ & $0.01[1]$ & 0.93 \\
\hline No & $152(14.49)$ & $97(14.56)$ & $55(14.36)$ & & \\
\hline \multicolumn{6}{|c|}{$\begin{array}{l}\text { Additional steps to consider to prevent } \\
\text { COVID-19 }\end{array}$} \\
\hline \multicolumn{6}{|c|}{ Creating awareness } \\
\hline Yes & $1046(99.62)$ & $664(99.70)$ & $382(99.48)$ & $0.31[1]$ & 0.58 \\
\hline No & $4(0.38)$ & $2(0.30)$ & $2(0.52)$ & & \\
\hline \multicolumn{6}{|c|}{ Restricting immigration } \\
\hline Yes & 826 (78.67) & $515(77.33)$ & $311(80.99)$ & $1.95[1]$ & 0.16 \\
\hline No & $224(21.33)$ & 151 (22.67) & $73(19.01)$ & & \\
\hline \multicolumn{6}{|c|}{$\begin{array}{l}\text { Encouraging infected persons to be in } \\
\text { quarantine or isolation }\end{array}$} \\
\hline Yes & $975(92.86)$ & $618(92.79)$ & 357 (92.97) & $0.01[1]$ & 0.92 \\
\hline No & $75(7.14)$ & $48(7.21)$ & $27(7.03)$ & & \\
\hline
\end{tabular}

${ }^{*} \mathrm{p}<0.05 ;{ }^{* *} \mathrm{p}<0.01 . \mathrm{df}=$ degrees of freedom.

responses for 'Do you wash your hands with handwash?' differed by gender $\left[\chi^{2}(1, N=1050)=21.81, \mathrm{p}<0.001\right]$. Furthermore, the responses for 'Do you wash your hands with soap?' differed by gender $\left[\chi^{2}(1, N=1050)=11.88\right.$, $\mathrm{p}<0.001]$. Answers for other statements or questions were not significantly associated with the gender of the respondents (Table 4).

\section{DISCUSSION}

Preventive and control measures regarding the virus are the most crucial, now as the COVID-19 has spread worldwide. The appropriate knowledge, attitude and preparedness towards COVID-19 among the general public are the backbone for ensuring any preventive or control measures. This study unveils the overall picture of a subset 
of Bangladeshi adults' knowledge, attitude and preparedness towards COVID-19.

Our results indicate that the vast majority of respondents reported COVID-19 as dangerous. Corresponding to our study, a Bangladeshi study showed that $96.7 \%$ of the respondents said COVID-19 is a hazardous disease ${ }^{17}$. It was claimed before that a higher perceived threat of fatal infection results in higher rates of preventive practices ${ }^{22}$. A substantial proportion of respondents from the current study gave an incorrect answer about the symptoms of COVID-19 as respondents did not know that diarrhea, fatigue, muscle pain and vomiting are symptoms of COVID-19. Those incorrect answers indicate poor knowledge, which may significantly affect control measures, as public knowledge is crucial in dealing with pandemics ${ }^{23}$. A possible reason for this poor knowledge can be the source of information, as social media were the primary source of COVID-19 information. In contrast, in the present study only few respondents sought information from doctors or family. Misleading and false information can spread in social media, which might misguide the general population regarding knowledge of COVID-19. With the global pandemic, widespread misinformation has also been reported that might lead to the concern of xenophobia globally, as reported by scientists and WHO official personnel ${ }^{24,25}$. Previous studies also showed a significant association between sources of information and knowledge ${ }^{9}$. The result is in line with studies conducted in Bangladesh, Vietnam, and China in which the main source of knowledge was social media ${ }^{9,26,27}$. This finding has significant gender difference showing females used social media more that the male counterparts to gather knowledge on COVID-19. This situation demands careful evaluation of sources and ensuring of authentic information regarding COVID-19.

A previous study reported that $67 \%$ of respondents believed COVID-19 can transmit through close contact with an infected person ${ }^{27}$ and another study showed almost half of the respondents were unaware about person-to-person transmission of COVID-19 ${ }^{28}$. Furthermore, the present study showed that $17.8 \%$ and $9.1 \%$ respondents had incorrect knowledge saying that COVID-19 cannot spread in warm weather and can spread via mosquitos, respectively. It was documented before that COVID-19 can be transmitted in hot and humid weather and mosquito bites cannot transmit COVID-1929. Possible explanation for this higher rate of incorrect knowledge can be the initial survey of this study, when people were confused with different myths spreading on social media. Communication between healthcare providers and the public at frequent intervals is recommended in order to overcome myths and to inform the public about health education ${ }^{30}$.

Moreover, $94.8 \%$ of respondents gave the correct answer saying that sick people should stay at home to prevent COVID-19, which is comparable to a previous study where $96.4 \%$ believed lockdown as an effective measure of transmission control ${ }^{31}$. Of note, $10.4 \%$ of respondents thought that antibiotics can cure COVID-19, which is comparable to a study which showed that $41.6 \%$ of participants believed antibiotics as the first-line treatment ${ }^{27}$.

In regard to attitude towards COVID-19, 98.2\% of the respondents agreed that they would like to stay in quarantine if any COVID-19 symptoms appear, which is comparable to a study where $97.9 \%$ participants agreed to isolation if needed $^{27}$. This positive attitude can be the result of correct knowledge among the participants ${ }^{27}$. In our study, $44.9 \%$ participants did not go out, which is comparable to previous studies where $87 \%$ did not go to any crowded place and $95 \%$ of participants did not attend any social events ${ }^{28,32}$. Data from other countries are in accordance with our findings which showed females were 3.6 times more likely to avoid going out than males ${ }^{32}$, and women were found to have a more responsible attitude than males who tended to show risky behaviors ${ }^{9}$. This finding might be attributable to the fact that males tend to be more occupied with the office and business work outside home than females in Bangladesh. It is worthy to mention that psychological factors (i.e. behavior induced by fear, misleading information) and concerns related to economy could be behind the limited agreement to obey governmental initiatives (i.e. lockdown) by posing serious pressure $^{33}$. This major finding highlights the importance of encouraging people in maintaining social distancing to prevent the transmission of COVID-19.

High positive preparedness was observed in washing hands more than 4 times a day with soap, which is similar to the findings of Maheshwari et al. ${ }^{34}$ who reported that 96.6\% participants increased their frequency of washing hands. In the present study, females washed hands with handwash more than males. This finding is consistent with other previous findings showing that men were less likely to take preventive measures than women ${ }^{35}$. In our study only few reported to never use masks. If avoidance of mask usage is not managed, this could impede the progression of COVID-19 transmission control in future ${ }^{36}$. According to experts' opinion, there prevails a lack of harmony towards the management of COVID-19 despite of having enough time ${ }^{37}$, which should be taken into account when adopting any intervention strategies.

\section{Strengths and limitations}

The findings are congruent for policy makers and other concerned authorities to address the gaps in public health knowledge, attitude and preparedness towards a pandemic like the COVID-19 by ensuring prompt yet adequate policy, effective health education programs, and short- and longterm interventions for improving COVID-19 response, prevention and control. The findings can also work as a baseline to understand public perception to contain any future outbreak in Bangladesh.

The study has some limitations to consider when interpreting the results. Firstly, the study was only able to 
include participants who had access to internet and were mostly educated due to the online nature of the survey. Educated people are more likely to have good knowledge and positive attitude towards COVID-19. Moreover, comparatively a higher percentage of students with lower age participated in the online survey. Thus, this may overestimate the overall result and cannot be generalized to the whole population. This problem might be overcome by replicating the study, by including all types of groups in the study population. Secondly, self-reported data and convenience sampling technique might affect the results as some biases (reporting bias, selection bias, social desirability bias) could not be ignored. Thirdly, determination of cause-effect mechanisms was not possible for the cross-sectional nature of the study. Future longitudinal study including focus group discussions and in-depth interviews are recommended.

\section{CONCLUSIONS}

Our findings suggest that public health education services, with special emphasis on disseminating correct knowledge with a focus on gender differences, are vital in order to encourage healthy behavior during such a pandemic. Males showed a higher tendency in believing the myths about COVID-19 than their female counterparts, which is alarming. Awareness programs should be emphasized, focusing on gender-specific proper information to ensure effective preventive measures. Furthermore, community-based health education programs and other interventions should be strengthened with the implementation of gender specific measures and policy to safeguard the general population by ensuring appropriate knowledge, positive attitudes and preparedness.

\section{REFERENCES}

1. World Health Organization. WHO Bangladesh COVID-19 Morbidity and Mortality Weekly Update (MMWU) No73. July 19, 2021. Accessed July 23, 2021. https://cdn.who. int/media/docs/default-source/searo/bangladesh/covid19-who-bangladesh-situation-reports/who_covid-19update_73_20210719.pdf?sfvrsn=a4ddc720_9

2. Hossain A, Rana J, Benzadid S, Ahsan GU. COVID-19 and Bangladesh. North South University; 2020. NSU Weekly Report 2. April 06, 2020. Accessed July 23, 2021. https:// drive.google.com/file/d/1Qpn6RYwH61fCQv6A69T4LSoso FH61K96/view

3. Bloch EM, Shoham S, Casadevall A, et al. Deployment of convalescent plasma for the prevention and treatment of COVID-19. J Clin Invest. 2020;130(6):2757-2765. doi:10.1172/JCI138745

4. Yap J, Lee VJ, Yau TY, Ng TP, Tor PC. Knowledge, attitudes and practices towards pandemic influenza among cases, close contacts, and healthcare workers in tropical Singapore: a cross-sectional survey. BMC Public Health. 2010;10(1):442. doi:10.1186/1471-2458-10-442

5. Leung GM, Quah S, Ho LM, et al. A Tale of Two Cities:
Community Psychobehavioral Surveillance and Related Impact on Outbreak Control in Hong Kong and Singapore During the Severe Acute Respiratory Syndrome Epidemic. Infect Control Hosp Epidemiol. 2004;25(12):1033-1041. doi:10.1086/502340

6. Abdel Wahed WY, Hefzy EM, Ahmed MI, Hamed NS. Assessment of Knowledge, Attitudes, and Perception of Health Care Workers Regarding COVID-19, A Cross-Sectional Study from Egypt. J Community Health. 2020;45(6):12421251. doi:10.1007/s10900-020-00882-0

7. Stuart RM, Abeysuriya RG, Kerr CC, et al. Role of masks, testing and contact tracing in preventing COVID-19 resurgences: a case study from New South Wales, Australia. BMJ Open. 2021;11(4):e045941. doi:10.1136/bmjopen-2020-045941

8. Ahmed MA, Jouhar R, Ahmed N, et al. Fear and Practice Modifications among Dentists to Combat Novel Coronavirus Disease (COVID-19) Outbreak. Int J Environ Res Public Health. 2020;17(8):2821. doi:10.3390/ijerph17082821

9. Zhong BL, Luo W, Li HM, et al. Knowledge, attitudes, and practices towards COVID-19 among Chinese residents during the rapid rise period of the COVID-19 outbreak: a quick online cross-sectional survey. Int J Biol Sci. 2020;16(10):1745-1752. doi:10.7150/ijbs.45221

10. Goni MD, Hasan H, Naing NN. Assessment of Knowledge, Attitude and Practice towards Prevention of Respiratory Tract Infections among Hajj and Umrah Pilgrims from Malaysia in 2018. Int J Environ Res Public Health. 2019;16(22):4569. doi:10.3390/ijerph16224569

11. Zhang M, Zhou M, Tang F, et al. Knowledge, attitude, and practice regarding COVID-19 among healthcare workers in Henan, China. J Hosp Infect. 2020;105(2):183-187. doi:10.1016/j.jhin.2020.04.012

12. Nikolich-Zugich J, Knox KS, Rios CT, Natt B, Bhattacharya D, Fain MJ. SARS-CoV-2 and COVID-19 in older adults: what we may expect regarding pathogenesis, immune responses, and outcomes. Geroscience. 2020;42(2):505-514. doi:10.1007/s11357-020-00186-0

13. Reuben RC, Danladi MMA, Saleh DA, Ejembi PE. Knowledge, Attitudes and Practices Towards COVID-19: An Epidemiological Survey in North-Central Nigeria. J Community Health. 2021;46(3):457-470. doi:10.1007/s10900-020-00881-1

14. Li S, Feng B, Liao W, Pan W. Internet Use, Risk Awareness, and Demographic Characteristics Associated With Engagement in Preventive Behaviors and Testing: Cross-Sectional Survey on COVID-19 in the United States. J Med Internet Res. 2020;22(6):e19782. doi:10.2196/19782

15. Alnakli Z. Saudi Arabians' Health Beliefs Pertaining to Middle East Respiratory Syndrome - Coronavirus (MERS-CoV): Knowledge, Attitudes, and Practices (KAP) Assessment. Dissertation. Arcadia University; 2016. Accessed July 23, 2021. https://scholarworks.arcadia.edu/cgi/viewcontent. cgi?article $=1006 \&$ context $=$ grad_etd

16. Banik R, Rahman M, Sikder MT, Rahman QM, Pranta 
MUR. Knowledge, attitudes, and practices related to the COVID-19 pandemic among Bangladeshi youth: a webbased cross-sectional analysis. J Public Health. 2021;1-11. doi:10.1007/s10389-020-01432-7

17. Ferdous MZ, Islam MS, Sikder MT, Mosaddek ASM, Zegarra-Valdivia JA, Gozal D. Knowledge, attitude, and practice regarding COVID-19 outbreak in Bangladesh: An online-based cross-sectional study. PLoS One. 2020;15(10):e0239254. doi:10.1371/journal.pone.0239254

18. Eysenbach G. Improving the Quality of Web Surveys: The Checklist for Reporting Results of Internet E-Surveys (CHERRIES). J Med Internet Res. 2004;6(3):e34. doi:10.2196/jmir.6.3.e34

19. Murray CJL, Vos T, Lozano R, et al. Disability-adjusted life years (DALYs) for 291 diseases and injuries in 21 regions, 1990-2010: a systematic analysis for the Global Burden of Disease Study 2010. Lancet. 2012;380(9859):2197-2223. doi:10.1016/S0140-6736(12)61689-4

20. Islam MR, Sultana MS, Khan AH, et al. Fear and depressive symptoms amid COVID-19: A cross-sectional pilot studyamong adult population in Bangladesh. Heliyon. 2021;7(7):e07395. doi:10.1016/j.heliyon.2021.e07395

21. Coronavirus disease (COVID-19) pandemic. World Health Organization. Accessed July 19, 2021. https:// ww w. who.int/emergencies/diseases/novelcoronavirus -2019 ? gclid=CjwKCAjwruSHBhAtEiwA_ qCppiN9TsjGzCjiOlQz5vIUIBuc8-yONAm1bC8WiVQ8rQHX gKGdK8pJ8RoCSwoQAvD_BwE

22. Alobuia WM, Missikpode C, Aung M, Jolly PE. Knowledge, Attitude, and Practices Regarding Vector-borne Diseases in Western Jamaica. Ann Glob Health. 2015;81(5):654-663. doi:10.1016/j.aogh.2015.08.013

23. Chirwa GC. "Who knows more, and why?" Explaining socioeconomic-related inequality in knowledge about HIV in Malawi. Sci Afr. 2020;7:e00213. doi:10.1016/j.sciaf.2019.e00213

24. Lai CC, Shih TP, Ko WC, Tang HJ, Hsueh PR. Severe acute respiratory syndrome coronavirus 2 (SARS-CoV-2) and coronavirus disease-2019 (COVID-19): The epidemic and the challenges. Int J Antimicrob Agents. 2020;55(3):105924. doi:10.1016/j.ijantimicag.2020.105924

25. Shimizu K. 2019-nCoV, fake news, and racism. Lancet. 2020;395(10225):685-686. doi:10.1016/S0140-6736(20)30357-3

26. Farhana KM, Mannan KA. Knowledge and perception towards Novel Coronavirus (COVID 19) in Bangladesh. International Research Journal of Business and Social Science. 2020;6(2):76-79. doi:10.2139/ssrn.3578477

27. Huynh G, Nguyen TNH, Tran VK, Vo KN, Vo VT, Pham LA. Knowledge and attitude toward COVID-19 among healthcare workers at District 2 Hospital, Ho Chi Minh City. Asian Pac J Trop Med. 2020;13(6):260-265. doi:10.4103/1995-7645.280396

28. Al-Hanawi MK, Angawi K, Alshareef N, et al. Knowledge, Attitude and Practice Toward COVID-19 Among the Public in the Kingdom of Saudi Arabia: A Cross-Sectional Study. Front Public Health. 2020;8:217. doi:10.3389/fpubh.2020.00217

29. World Health Organization. Advice on the use of masks in the context of COVID-19: interim guidance, 6 April 2020. World Health Organization; 2020. Accessed July 1, 2020. https:// apps.who.int/iris/handle/10665/331693

30. Nour MO, Babilghith AO, Natto HA, Al-Amin FO, Alawneh SM. Knowledge, attitude and practices of healthcare providers towards MERS-CoV infection at Makkah hospitals, KSA. International Research Journal of Medicine and Medical Sciences. 2015;3(4):103-112. Accessed July 23, 2021. http:// www.netjournals.org/pdf/IRJMMS/2015/4/15-046.pdf

31. Asraf H, Garima T, Singh BM, Ram R, Tripti RP. Knowledge, attitudes, and practices towards COVID-19 among Nepalese Residents: A quick online cross-sectional survey. Asian J Med Sci. 2020;11(3):6-11. doi:10.3126/ajms.v11i3.28485

32. Hamza MS, Badary OA, Elmazar MM. Cross-Sectional Study on Awareness and Knowledge of COVID-19 Among Senior pharmacy Students. J Community Health. 2021;46(1):139146. doi:10.1007/s10900-020-00859-z

33. Bali S, Stewart KA, Pate MA. Long shadow of fear in an epidemic: fearonomic effects of Ebola on the private sector in Nigeria. BMJ Glob Health. 2016;1(3):e000111. doi:10.1136/bmjgh-2016-000111

34. Maheshwari S, Gupta PK, Sinha R, Rawat P. Knowledge, attitude, and practice towards coronavirus disease 2019 (COVID-19) among medical students: A cross-sectional study. Journal of Acute Disease. 2020;9(3):100-104. doi:10.4103/2221-6189.283886

35. ALdowyan NM, Ahmed AS, El-Gharabawy RM. Knowledge, Attitude and Practice (KAP) Study about Middle East Respiratory Syndrome Coronavirus (MERS-CoV) among Population in Saudi Arabia. Int Arch Med. 2017;10(254):112. doi:10.3823/2524

36. Coronavirus disease (COVID-19) advice for the public: Mythbusters. World Health Organization. May 5, 2021. Accessed July 1, 2020. https://www.who.int/emergencies/ diseases/novel-coronavirus-2019/advice-for-public/mythbusters

37. [Coronavirus: One month after the first patient was identified, where is Bangladesh?] Article in Bengali. BBC News. April 6, 2020. Accessed July 1, 2020. https://www. bbc.com/bengali/news-52207223 


\section{ACKNOWLEDGMENTS}

We thank all the those who participated in the study. We also thank the research assistants (volunteers) who supported online data collection for this study.

\section{CONFLICTS OF INTEREST}

The authors have completed and submitted the ICMJE Form for Disclosure of Potential Conflicts of Interest and none was reported.

FUNDING

There was no source of funding for this research.

\section{ETHICAL APPROVAL AND INFORMED CONSENT}

Ethical approval was obtained from the Institutional Review Board (14-122020; BBEC, JU/ M 2020/COVID-19/12(1)), 'Biosafety, Biosecurity \& Ethical Committee' of the Jahangirnagar University. Informed consent was obtained from the participants. All participants signed an electronic consent form.

\section{DATA AVAILABILITY}

The data supporting this research are available from the authors on reasonable request.

\section{AUTHORS' CONTRIBUTIONS}

SS: conceptualization, methodology, investigation, writing of original draft, reviewing and editing, validation. AHK: conceptualization, investigation, formal analysis, data curation, writing of original draft, validation. MRI: conceptualization, methodology, writing of original draft. SH: conceptualization, supervision, writing, reviewing and editing, validation. MTH: writing, reviewing and editing, validation. MTS:Writing, reviewing and editing, validation.

\section{PROVENANCE AND PEER REVIEW}

Not commissioned; externally peer reviewed. 